\title{
Martin Hilpert, Ten Lectures on Diachronic Construction Grammar. Leiden, Boston: Brill, 2021
}

\section{Joanna Podhorodecka}

Pedagogical University of Krakow, Poland

joanna.podhorodecka@up.krakow.pl

Diachronic Construction Grammar $(\mathrm{DCxG})$ is a relatively recent strand of research that emerged at the turn of the $21^{\text {st }}$ century when the grammaticalization theory took "a constructionist turn" (Noël, Colleman 2021: 664). It focuses on the crucial role of constructions and the frequency of their usage in the processes of language change. The recent decade has brought the publication of a textbook-type introduction to the field, which defines its basic concepts and tenets (Traugott, Trousdale 2013), as well as two major edited volumes (Barðdal et al. 2015; Sommerer, Smirnova 2020).

Martin Hilpert's contribution to constructionist research, in addition to a number of articles, includes two diachronic-themed monographs: Germanic Future Constructions (2008) and Constructional Change in English (2013), as well as a popular introductory textbook, now in its second edition, Construction Grammar and Its Application to English ([2014] 2019). The reviewed work is the latest item in the series Distinguished Lectures in Cognitive Linguistics, open-access publications which chronicle series of lectures delivered at China International Forum on Cognitive Linguistics by key figures within the field. The e-book contains links to supplementary materials (audio files and presentation slides) and presupposes only the basic knowledge of tenets and concepts of Cognitive Linguistics, so it can be approached by a relative novice. In the first two lectures, the author provides the theoretical foundation for the whole series, while the other talks focus on particular problems and case studies, exploring a wide range of corpus-based and experimental methods utilized by Construction Grammar.

Lecture 1 ('What is Construction Grammar?') succinctly outlines the fundamentals of the constructionist approach to language, in which different aspects of linguistic knowledge are reconceptualized in terms of knowledge of the various types of constructions: pairings of form (phonological, morphological and syntactic) and meaning (semantic, pragmatic, discoursefunctional). Constructions tend to be idiosyncratic and non-compositional, and all of them are meaningful, irrespective of their degree of complexity or schematicity. The meaning of 
constructions is reflected in statistically significant associations between syntactic patterns and lexical elements that can fill them - this observation together with its application in corpus research constitutes a major recurring theme in the subsequent lectures. The author goes on to enumerate the strategies for identifying constructions on the basis of their irregular characteristics, non-compositional meaning, idiosyncratic constraints and collocational preferences. The lecture closes with a brief introduction to some new developments in the field and several controversies being currently debated, including the status of morphemes (as constructions or parts of constructions), the exact techniques of establishing collocational measures (raw frequencies or relative frequencies) and the question how grammatical information is represented (just once at the most abstract level and subsequently inherited by more specific constructions or redundantly at different levels of abstraction).

Lecture 2 ('Taking a Constructional Approach to Language Change') offers a coherent description of the diachronic constructional approach in terms of the basic ideas introduced in the previous lecture. Language change is presented in terms of shifts in a constructional network: the emergence of new nodes (constructionalization), change in form or meaning of existing nodes (constructional change), the emergence or disappearance of links in the network or changes in their connection strength. As the constructionist framework is inherently usagebased, Hilpert rightly emphasizes the role of diachronic corpus data and their analysis (e.g. how shifting associations between constructions and lexical elements provide evidence of semantic change), as well as the impact of cognitive and social factors as driving forces of these changes.

Rather than juxtaposing broadly understood cognitive perspective with generative and formal approaches, the author compares various cognitive theories, focusing mainly on how DCxG overlaps with the grammaticalization theory, which studies the development of less grammatical linguistic items (e.g. content words) into more grammatical items (e.g. function words or inflectional affixes) (Bergs 2017: 369-370). The two theories are increasingly convergent, but not identical: the grammaticalization theory is narrower in its scope, but makes testable predictions of future developments, as it assumes that grammaticalizing entities undergo a set of unidirectional processes. On the one hand, it does not cover lexical-semantic changes (narrowing, amelioration), on the other, it is fully capable of forming meta-generalizations about whole groups of constructions (e.g. loss of morphology or large scale sociolinguistic change).

Lecture 3 ('Three open questions in Diachronic Construction Grammar') addresses three currently unresolved problems within $\mathrm{DCxG}$, the first of which is the exact nature of its object of study (linguistic forms or their mental representations), while the second contested issue relates to defining the process of constructionalization. Hilpert subscribes to Traugott and 
Trousdale's (2013: 22-26) division into constructionalization (emergence of new constructions) and constructional change (formal or semantic change within the existing ones), which is regarded as increasingly problematic by many other scholars (see Smirnova, Sommerer 2020: 12-17). At the same time, Hilpert admits that the distinction is somewhat relative and very much depends on the perspective and time frame adopted by the researcher (e.g. a sequence of constructional changes may eventually result in full constructionalization). The author convincingly argues that the distinction is in fact not very useful, and instead proposes a finegrained matrix of possible changes, where the type of change (emergence, strengthening, weakening, and disappearance) intersects with its scope (form, meaning, connection in the network). This classification covers a whole range of processes, among which constructionalization proper constitutes only a minority.

The third open question covered by the lecture relates to knowledge representation within the constructional network: the amount of knowledge contained in the nodes as opposed to the connections between them. Hilpert is of the opinion that $\mathrm{DCxG}$ has so far placed too much emphasis on the nodes themselves and makes a compelling case for a model where more information is stored in the way the nodes are interconnected. The author proposes modelling the associative links between constructions and lexical items that can fill their slots, and provides the example of a case study of changing collocational preferences of modals over the last century and a half, illustrating how may has shifted towards a more epistemic meaning.

Lecture 4 ('Shifts in collocational preferences') further elaborates on how changes in the collocation patterns of constructions reflect more systematic processes, such as those described by the grammaticalization theory: with time constructions tend to broaden the range of their collocates and meanings. Discussing the development of the way construction (as in to elbow one's way through the crowd) and future forms in Germanic languages, Hilpert effectively demonstrates that relative frequencies rather than raw frequencies provide the best measure of these changes, and explains the mechanics and the logic behind collostructional analysis (Stefanowitsch, Gries 2003) - a statistical tool for identifying lexical items that occur in a construction significantly more often than expected, given their overall frequency in the corpus. Hilpert provides illustrative examples of the way the technique can be applied in diachronic studies to identify the elements that are most characteristic of a particular time period, as well as in contrastive studies to compare corresponding constructions across languages.

The main focus of Lecture 5 ('How Constructional Networks grow and fade') is noun morphology and word-formation, as exemplified by the changes in the function, frequency and lexical scope of the V-ment construction (e.g. treatment, judgment, agreement). Hilpert follows 
the development of the structure from its first occurrences in Latin loanwords in Old English, through its nativization in the $13^{\text {th }}$ century, to the present day, when it accounts for many relatively infrequent nouns, but is no longer productively used to coin new forms. The author clearly explains the workings of several statistical techniques for the interpretation of diachronic corpus data: the hierarchical clustering used to divide the corpus into time periods on the basis of the variability in the data, and the multivariate analysis subsequently applied to decide which features characterize each of thus established stages in the development of the construction.

Lecture 6 ('Competition in Constructional Change') examines constructions which are in mutual competition due to similar functions. While choosing between two competing forms connected to a single meaning in the constructional network, speakers will typically select the one where this link is stronger, which may eventually lead either to substitution or differentiation between the two constructions. This is the case with English possessive determiners (my-mine; thy-thine), whose two alternative forms originally shared an identical function. In order to trace their gradual differentiation, the analysis relies on logistic regression (see e.g. Levshina 2015: 253-276) - a multivariate statistical tool that estimates the influence of individual factors (e.g. phonetic context, stress, priming, formality level) on the likelihood of the speaker choosing one of the two forms. On the basis of the similarities revealed in the analysis, Hilpert offers solid arguments for treating the evolution of both the first and the second person determiners as a single constructional change: a competition that has proceeded to complete substitution, influenced by various linguistic and extralinguistic factors, occurring at different times with varying strength.

Lecture 7 ('Differentiation and attraction in Constructional Change') explores constructional paradigms evolving over time, with some constructions becoming more similar and some more distinct from one another. The case study discussed in this lecture involves concessive parentheticals: structures including a concessive linker (e.g. while/if/although) and a predicative element (mainly adjective or noun) embedded in a matrix clause, whose function consists in cancelling an implicature or a potential conclusion (e.g. Though crude, the method is effective.). Hilpert traces their development over the last 150 years to establish how the construction originated: through a reduction of full clauses or through analogy to other clause types (e.g. conditional or time clauses). The analysis shows that there is a large degree of overlap in the syntax and collocations of concessive parentheticals and full concessive clauses, which speaks for the reduction hypothesis. In order to visualize how the constructional paradigm changes over time, Hilpert calculates similarity measures between different syntactic variants of concessive parentheticals and converts them into a distance matrix. On the basis of such 
development paths of various versions of the construction, the author persuasively argues that in this paradigm local generalizations are more prominent and that we are in fact dealing with a construction family rather than a single overarching schema.

In Lecture 8 ('The Asymmetric Priming Hypothesis') Hilpert sets out to discover whether the titular hypothesis (see Jäger, Rosenbach 2008) can account for the unidirectionality of grammaticalization processes in terms of general cognitive processes which operate in actual communication. Asymmetric priming takes place when one linguistic item strongly evokes another, but not vice versa. If through the process of grammaticalization form A turns into form $\mathrm{B}$, then A should prime B and not the other way round. The lecture recounts psycholinguistic experiments and corpus studies of a set of items that function both as lexical and grammatical units (e.g. do as a lexical verb and auxiliary, lexical get and get-passive, temporal and causal since) conducted in order to establish if the lexical elements prime their grammatical counterparts i.e. whether in this combination (lexical + grammatical) the items are processed faster by speakers or occur more frequently in the corpus. Both methods discover no evidence for the hypothesis, revealing instead an opposite tendency: lexical elements strongly slow down the grammatical ones, which can be explained by the phenomenon of horror aequi - speakers have trouble processing the same form twice. The unidirectionality of semantic change in grammaticalization thus requires a different explanation.

Lecture 9 ('The upward strengthening hypothesis') investigates how higher-level patterns are established and strengthened in the constructional network. The general consensus within the usage-based approach seems to be that mental representations of linguistic units are more strongly entrenched if they are frequently activated. The usage of a particular expression strengthens not only the expression itself, but also more abstract schemas that motivate it. The question is how far up the activation goes and what triggers it. Hilpert conducts a diachronic study of English noun-participle compounds (e.g. goal-oriented, usage-based), comparing them with the passive construction in order to establish whether they have changed in similar ways. The data indicate that the compounds have increased dynamically over the last 200 years, both in overall frequency and in type frequency, but they have developed independently from the passive: the increase in particular participle types in compounds is not related to the corresponding developments in the passive construction. The analysis convincingly demonstrates that the amount of upward strengthening triggered by a particular lexeme is conditioned by its ease of categorization, frequency and salience, since infrequent and unusual units rely more strongly on the generic schema to be processed. 
Lecture10 ('Constructional change and distributional semantics') rounds up the series with some more comprehensive discussion of the distributional methods applied in earlier studies, in particular the semantic vector spaces, a technique for visualizing the semantic areas occupied by a construction on the basis of its collocation patterns. Hilpert clearly elucidates its mechanics, illustrating the argument with two case studies: the first one follows the development of many $a$ NOUN construction, which is archaic and infrequent in present-day English, but surprisingly still quite productive. The second study investigates the possible origins of the permissive get + infinitive construction (as in We'll get to see the show.) on the basis of a comparison of semantic spaces occupied by the construction with other related structures that could have given rise to it. The analysis shows that the permissive get most likely developed from its inchoative meaning (describing change of state, e.g. get angry, get better), as the degree of overlap is greatest between the semantic areas occupied by the two constructions. The author closes the talk by returning to the main theme of the series: syntactic patterns are not meaningless templates since they show significant associations with particular types of lexical items, and diachronic shifts in those associations can be modelled in terms of changes in connections between the elements of the constructional network.

Ten lectures on Diachronic Construction Grammar focus on the empirical basis of the framework: all studies discussed are corpus-driven and employ a wide range of statistical methods of analysis. The recurring theme of the series is the need for researchers to put more emphasis on the connections between the nodes in the constructional network, i.e. on the relationships between different constructions as well as between constructions and their lexical preferences. The author shows how changes in such links can account for various aspects of language change as well as for the mutual feedback between synchronic and diachronic aspects of language.

The very format of the publication is a step towards more open and more inclusive scholarship of the digital era: the lectures are open-access, available both as an e-book and as sound files, so they can be either read or listened to on various electronic devices. PowerPoint slides are incorporated into the text and help the reader focus on the main points of the argument, which is generally useful even if it means repeating some of the information. The only technical problem seems to be the animated graphs in the last two lectures, which are not provided in a playable format.

The written version keeps the easy conversational style of a talk, edited to improve clarity. The lectures are relatively easy to follow, with plenty of thought-provoking and exhaustively discussed examples of various diachronic changes, which constitute the greatest strength of the 
text - the lecturer convincingly demonstrates how the changing collocational preferences reflect subtle shifts in the meaning and function of constructions, which is clearly explained, welldocumented with corpus data and genuinely interesting. The content is approachable and beginner-friendly, despite the complex subject matter and advanced statistical techniques discussed in most of the lectures. Hilpert leads the reader through the stages of data collection and analysis, providing step-by-step explanations and clarifying the logic behind the process, offering an interesting glimpse of the mechanics of diachronic corpus research. All of the above make the publication suitable for students and scholars representing other theoretical frameworks, as the Lectures are an accessible and enjoyable introduction to Diachronic Construction Grammar.

\section{References}

Barðdal, Jóhanna, Elena Smirnova, Lotte Sommerer, Spike Gildea (eds.) (2015) Diachronic Construction Grammar. Amsterdam: John Benjamins.

Bergs, Alexander (2017) "Diachronic Approaches." [In:] Barbara Dancygier (ed.) The Cambridge Handbook of Cognitive Linguistics. Cambridge: Cambridge University Press; 361-375.

Hilpert, Martin (2008) Germanic Future Constructions: A Usage-based Approach to Language Change. Amsterdam, Philadelphia: John Benjamins.

Hilpert, Martin (2013) Constructional Change in English: Developments in Allomorphy, Word Formation, and Syntax. Cambridge: Cambridge University Press.

Hilpert, Martin ([2014] 2019) Construction Grammar and Its Application to English. Edinburgh: Edinburgh University Press.

Jäger, Gerhard, Anette Rosenbach (2008) "Priming and Unidirectional Language Change." Theoretical Linguistics 34 (2); 85-113.

Levshina, Natalia (2015) How to Do Linguistics with R: Data Exploration and Statistical Analysis. Amsterdam, Philadelphia: John Benjamins.

Noël, Dirk, Timothy Colleman (2021) “Diachronic Construction Grammar.” [In:] Xu Wen, John R. Taylor (eds.) Routledge Handbook of Cognitive Linguistics. New York, London: Routledge; 662-675.

Smirnova, Elena, Lotte Sommerer (2020) "Introduction: The Nature of the Node and the Network - Open Questions in Diachronic Construction Grammar.” [In:] Lotte Sommerer, 
Elena Smirnova (eds.) Nodes and Networks in Diachronic Construction Grammar. Amsterdam, Philadelphia: John Benjamins; 1-42.

Sommerer, Lotte, Elena Smirnova (eds.) (2020) Nodes and Networks in Diachronic Construction Grammar. Amsterdam, Philadelphia: John Benjamins.

Stefanowitsch, Anatol, Stefan Th. Gries (2003) "Collostructions: Investigating the Interaction Between Words and Constructions." International Journal of Corpus Linguistics 8 (2); $209-243$.

Traugott, Elizabeth C., Graeme Trousdale (2013) Constructionalization and Constructional Changes. Oxford: Oxford University Press. 